\title{
Dinosaur prints lead to crediting row
}

An article on Croatian dinosaur tracks that help to reveal the tectonic movements responsible for the creation of the Balkans has set off a modern-day continental clash. The situation raises questions about how far palaeontologists should have the right to prevent others from publishing on sites of interest that they discover.

The huge sauropod footprints, dating from about 95 million years ago, were discovered in 2004 on the island of Hvar by a team from the Croatian Natural History Museum in Zagreb, led by Michael Caldwell of the University of Alberta in Edmonton, Canada. The museum announced the discovery of the site to the press. But before the researchers could publish their study in the scientific literature, a competing group from the University of Zagreb went to the site and then published an article reporting the tracks. The article did not credit the discovery team, and an angry Caldwell has demanded its retraction.

The disputed article was published last December in the journal Cretaceous Research (A. Mezga et al. Cretac. Res. 27, 735-742; 2006). The lead author was palaeontologist Aleksandar Mezga, working with three Croatian colleagues and a Swiss researcher.

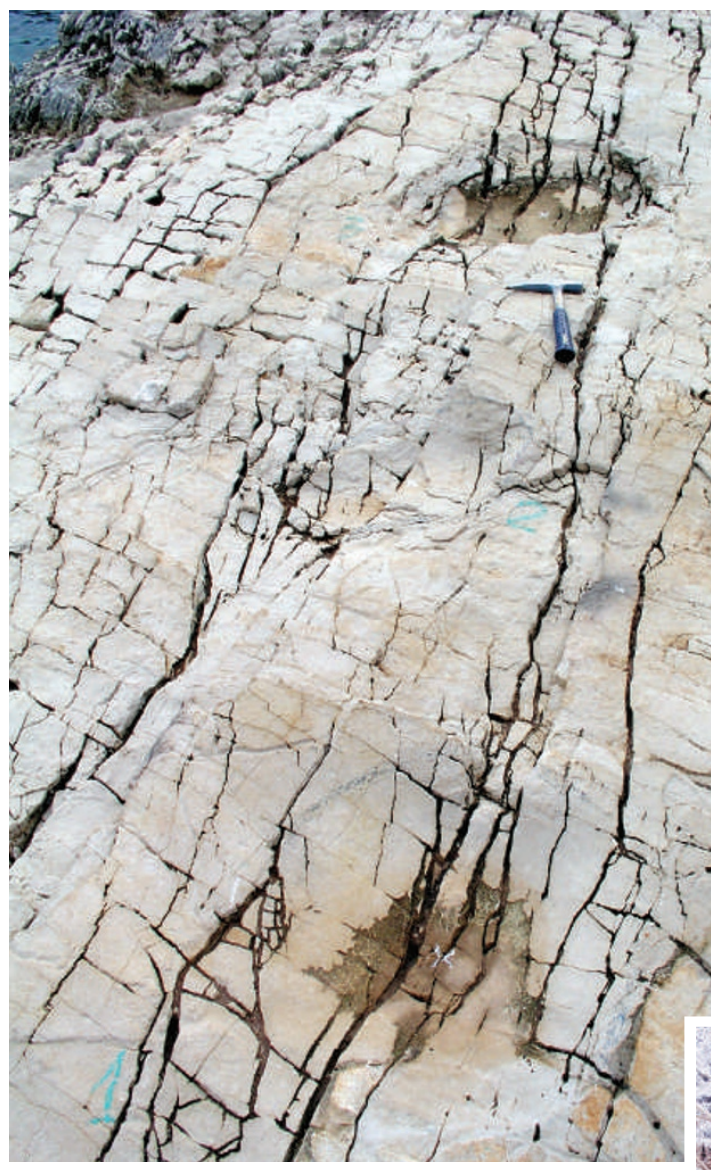

Faux pas? Dinosaur footprints discovered by Michael Caldwell (inset) and his team have resulted in discord.

Caldwell says he believes that the publication amounts to "intellectual theft", because it leaves his team unable to publish the discovery as its own. Caldwell's colleagues in Croatia declined to speak to Nature, but e-mails from them provided by Caldwell suggest they support his interpretation of events. For example, when he learned of the article in February, Jakov Radovcic, a Croatian sedimentologist working with Caldwell, wrote: "I was really shocked. I was not aware of the... behaviour of my colleagues from Zagreb."

Mezga, however, insists that he and his team have done nothing wrong. "Every single word... is our intellectual property," he told Nature. Because nothing had been published on the study site, Mezga says, he considered it open for reporting, although he acknowledges that he never contacted the discovery team to discuss the issue.

David Batten, a researcher at the University of Manchester, UK, and editor-in-chief of Cretaceous Research at the time the article was published, told Nature that the journal is considering Caldwell's request for a retraction. Such a retraction would be "very unusual", says Catherine Badgely of the University of Michigan in Ann Arbor and president of the US-based Society of Vertebrate Paleontology. Documented instances of misappropriation of palaeontological sites are rare, surfacing about every five years, Badgely notes. But she welcomes discussion of the issue: "It is good this is being brought out."

In this case, the tracks of a long-necked, plant-eating sauropod known as a titanosaur provide insight into massive tectonic shifts that occurred around 100 million years ago. The land mass that is now Africa was then shifting north against the Eurasian continent, raising and lowering geological structures across what have become the Balkan nations.
The dinosaur tracks are the oldest to have been found in that region. $\frac{\vec{N}}{\Sigma}$ But they also represent the most $\varangle$ recent signs of life on a geological plain called the Adriatic-Dinaric carbonate platform, before it sank beneath the sea 94 million years ago. And they provide an important clue about what other land the platform was connected to at the time.

Caldwell and his colleagues were exploring Hvar's rocky shoreline when they happened upon the 10 pad marks - each about 30 centimetres long - in a 65-squaremetre area of ground.

It is common for museums to announce such discoveries, and the Hvar site drew wide news coverage. The second Zagreb team started working on the site within a couple of months. They brought with them Christian Meyer, an authority on dinosaur tracks and director of the Natural History Museum in Basel, Switzerland. When contacted by Nature, Meyer declined to comment on the team's rights to the site, referring inquiries to his Croatian colleagues. But in an e-mail sent to Caldwell in February, he said his colleagues had told him no one else was studying the tracks.

Actually, Caldwell's team was analysing tiny plankton fossils to pinpoint the date of the tracks. Those studies were delayed when samples being shipped from Croatia to Edmonton were misplaced for six months by an airline.

Italian palaeontologist Fabio Dalla Vecchia was one of the reviewers of the Cretaceous Research article. He says he pointed out to the journal and the authors the need to fully credit the tracks' discoverers. But this did not happen (the journal admits receiving the request, but says that it was misunderstood). "I had nasty experiences in Croatia," adds Dalla Vecchia. "The groups fight each other there."

Caldwell says he is sad that things didn't work out differently. "This could have been such a good thing for Croatian research." Rex Dalton 